\title{
Ampelousia (Cap)
}

E.B.

\section{OpenEdition}

Journals

Édition électronique

URL : http://journals.openedition.org/encyclopedieberbere/2482

DOI : 10.4000/encyclopedieberbere.2482

ISSN : 2262-7197

\section{Éditeur}

Peeters Publishers

\section{Édition imprimée}

Date de publication : 1 septembre 1986

Pagination : 605-606

ISBN : 2-85744-282-3

ISSN : 1015-7344

\section{Référence électronique}

E.B., «Ampelousia (Cap) », Encyclopédie berbère [En ligne], 4 | 1986, document A200, mis en ligne le 01 décembre 2012, consulté le 13 octobre 2020. URL : http://journals.openedition.org/ encyclopedieberbere/2482; DOI : https://doi.org/10.4000/encyclopedieberbere.2482

Ce document a été généré automatiquement le 13 octobre 2020

(c) Tous droits réservés 


\section{Ampelousia (Cap)}

E.B.

1 On lit dans le t. II de l'Histoire ancienne de l'Afrique du Nord de S. Gsell : « Le Cap Spartel, appelé dans l'Antiquité le Cap des Vignes, Ampelusia pour les Grecs, Cotès pour les Africains), contenait une grotte d'Hercule. » (p. 169).

2 L'indentification de l'Ampelusia Promontorium (Pomponius Mela I, 25 ; Pline V, 2) avec le Cap Spartel ne fait aucun doute. Pomponius Mela indique que les Africains donnent au Cap Ampelusia un autre nom qui aurait le même sens. Il semble bien que cet autre nom est Kotès (Ptolémée IV, I, 2 Muller, p. 572) ou Kôteis, (Strabon XVII, 3, 2) donné par ces auteurs à ce même cap. On en déduit que ce mot sert à désigner la vigne mais est-il intrinsèquement africain, c'est-à-dire libyque $(=$ berbère) ? Il ne semble pas que les Berbères aient conservé une racine KTS ayant une relation quelconque avec la vigne ou le raisin, aussi plusieurs auteurs ont très tôt pensé que Kotès était un nom phénicien (Vivien de Saint-Martin, Movers, Bochart...). Il ne serait pas inutile de rechercher, aussi, une possible origine ibérique de ce toponyme qui a servi, en outre, à désigner le golfe au sud du Cap Spartel et une ville que Pline nomme Cottae.

\section{BIBLIOGRAPHIE}

VIVIEN DE SAINT MARTIN Le nord de l'Afrique dans l'Antiquité grecque et romaine. Étude historique et géographique, Paris, 1863, p. 349 et 418.

TISSOт Ch. Recherches sur la géographie comparée de Maurétanie Tingitane, Mémoire de l'Académie des Inscriptions et Belles-lettres, IX, 1878.

PONSICH M. Recherches archéologiques à Tanger et dans sa région, Paris, C.N.R.S., 1970. 
DESANGES J. Recherches sur l'activité des Méditerranéens aux confins de l'Afrique, École française de Rome, 1978.

INDEX

Mots-clés : Antiquité, Géographie, Maroc 